\title{
EL ESTADO DEL PERSONAL INQUISITORIAL DE MALLORCA A FINALES DEL SIGLO XVIII
}

\author{
The State of the Inquisitorial Staff of Mallorca at the End of the 18th Century
}

\section{Antoni Picazo Muntaner \\ a.picazo@uib.es \\ Universitat de les Illes Balears, España}

Fecha de recepción: 18/02/2021

Fecha de aceptación: 31/03/2021

RESUMEN: El análisis de las fuentes documentales existentes en el Archivo Histórico Nacional, de la serie Inquisición, permite profundizar cómo estaba diseñada la estructura interna del tribunal del Santo Oficio del reino de Mallorca a finales del siglo XVIII. Su actividad ya apuntaba a que estaba en decadencia absoluta. Las únicas actuaciones se centraban en la persecución de libros prohibidos o en la depuración de responsabilidades entre los religiosos acusados de solicitaciones. Entre los objetivos previstos destacaríamos valorar los gastos de personal y determinar quiénes formaban parte de este y con quiénes estaban vinculados. La principal conclusión que emana de este estudio es que en determinados casos existió una verdadera cooptación en la transmisión de los oficios, validada y permitida por el propio Consejo de la Suprema. Otra de las conclusiones que hemos alcanzado es la de valorar las conexiones que se dieron en la institución inquisitorial, especialmente entre los altos cargos. Configuraban una verdadera red de poder que se extendía gradualmente por todos los territorios de la Corona. Finalmente, clarificamos las diferencias existentes, en materia de personal entre la isla mayor, Mallorca, y las dos más pequeñas. Ibiza y, especialmente, Menorca. En esta última, tras la primera ocupación británica, el Santo Oficio había quedado desmantelado del todo.

Palabras clave: Inquisición; siglo XVIII; Mallorca; personal; gasto.

ABSTRACT: The analysis of the documentary sources existing in the National Historical Archive, from the Inquisition series, allows us to deepen how the internal structure of the court of the Holy Office of the kingdom of Mallorca was designed at the end of the 18th century, when its activity already indicated that it was in decline absolute and the only actions focused on the prosecution of 
prohibited books or the purging of responsibilities among religious accused of solicitations. Among the planned objectives we would highlight that of evaluating personnel costs and determining who was part of it, and with whom they were related. The main conclusion that emanates from this study is that in certain cases there was a true co-option in its transmission that was validated and allowed by the Supreme Council itself. Another of the conclusions that we have reached is to assess the connections that were made in the inquisitorial institution, especially among senior officials, thus configuring a true network of power that gradually spread throughout the territories of the Crown. Finally, we clarify the differences in personnel between the largest island, Mallorca, and the two smaller ones, such as Ibiza and, especially, Menorca. The latter after the first British occupation, the Holy Office had been completely dismantled.

Keywords: Inquisition;18th century; Mallorca; personnel; expense.

SUMARIO: 1. Introducción. 2. La alta jerarquía. 2.1. El inquisidor. 2.2. El fiscal. 3. Los oficiales. 4. Consultores y familiares. 5. Los oficiales en Menorca e Ibiza. 6. Conclusiones. 7. Referencias bibliográficas.

\section{INTRODUCCIÓN}

El Santo Oficio, como institución, estaba formado por una maquinaria administrativa muy compleja, con una rígida jerarquía en cuanto a su personal y un corpus legal con normas, leyes y códigos complicados. Empero, estaba constituida por hombres que vivían un momento histórico muy concreto. En consecuencia, la Inquisición siempre fue hija de su tiempo. Los individuos que la representaban eran hijos de su época, y tenían unas aspiraciones y deseos muy determinados. Y cada momento histórico tiene sus problemas, sus crisis, sus ansiedades, sus miedos, sus luces y sus sombras. No es lo mismo la dinámica política y económica que conformó el reinado de los Reyes Católicos que la que marcó la de los Borbones en el siglo XVIII. Por eso mismo, y en grandes líneas, podemos afirmar que la Inquisición del reino de Mallorca siguió las mismas pautas que las del resto de España. Una primera etapa marcada por la uniformidad religiosa, por la persecución de judaizantes que abarcó de finales del siglo XV a principios del siglo XVI. Y otra, menos activa, que se desarrolló durante casi todo el siglo XVI y buena parte del siglo XVII, determinada por una atonía muy clara. Los procesos contra judaizantes desaparecieron. No obstante, emergieron los que se activaron contra renegados, aunque proporcionalmente mucho menores que los anteriores $y$, en el siglo XVII, vemos algunos (no muy numerosos, por cierto) procesos contra hechiceras. A finales del XVII, y con un espacio de tiempo muy breve (1677-1691), se dio un repunte muy fuerte en los procesos contra judaizantes, que en Mallorca a partir de esas fechas tomarán el nombre de chuetas. Ya en el siglo XVIII la actividad inquisitorial estaba en franca decadencia cuando el gran enemigo, tanto del Estado como de la propia Iglesia, se 
materializaba en las ideas ilustradas que procedían de Francia. En la época que está centrado este estudio (1793), por tanto, el problema fundamental al que tenían que enfrentarse fue el del control ideológico, la persecución de ideas en lo que parecía un nuevo resurgir que se reflejó, tal y como señala Marina Torres (2010, p. 209) en un incremento de la demanda de títulos inquisitoriales. Un ejemplo significativo es el estudio de Fernando Gil (2017) de los procesos contra masones y libros prohibidos, y su divulgación, aunque, en este aspecto, la Real Cédula dictada por Carlos III reducía la capacidad interventora del Santo Oficio en esta materia. O incluso contra determinadas prácticas profesionales, como el proceso contra el doctor Fiol por proposiciones que se vio en Mallorca, y que Gerard Marí (2007) estudió en el caso catalán.

\section{LA ALTA JERARQUÍA}

\subsection{El inquisidor}

Sin duda alguna, el primero de los grandes representantes del tribunal de distrito de Mallorca a finales del siglo XVIII fue su inquisidor, el doctor fray José Albert Gil, natural de Albaida, Valencia. José Albert cursó estudios de Filosofía en la Universidad de Valencia durante tres años; los tres años siguientes los dedicó al estudio de leyes, completándolos y ampliándolos con uno de cánones. Fue en esa universidad donde alcanzó el grado de doctor. Poco tiempo después, y tras realizar el oportuno y perceptivo expediente, recibió el hábito de Montesa ${ }^{1}$. Pasó inmediatamente a residir en el colegio de esa orden, concretamente en el de San Jorge, de Valencia, donde regentó durante seis años cursos de leyes y cánones. En su labor profesional hizo tres oposiciones a las cátedras de leyes para esa misma universidad. En 1771 se le concedió el curato de Benirraes, de la orden de Montesa; y en 1778 el curato del Bailío de Carpesa, al que no llegó a servir puesto que el rey le concedió el priorato del Santo Convento de su orden del cual tomó posesión el 22 de febrero de 1794. El 13 de marzo de ese año el arzobispo de Salamanca, Felipe Beltrán Serrano (que también había ejercido una cátedra en la misma Universidad de Valencia), y que era Inquisidor General, le nombró promotor fiscal del tribunal de Llerena. Poco tiempo después, concretamente el 25 de noviembre de 1779, le concedió el mismo cargo para la plaza de Mallorca, tomando posesión de esta apenas un mes después, el 27 de diciembre de $1779^{2}$.

${ }^{1}$ Archivo Histórico Nacional, Madrid / Órdenes Militares / Religiosos de Montesa / Exp. 8, «Expediente de pruebas de José Albert Gil Alcober Lloret, natural de Albayda, para el ingreso como religioso de la Orden de Montesa, 1752».

2 Ibidem, fol. 3. 
Tanto sus conexiones con destacados miembros de la Suprema como de la misma Corte facilitaron que el 3 de mayo de 1782 el Inquisidor General le nombrase inquisidor de Mallorca, previo expediente de limpieza de sangre y genealogía, que superó sin ningún tipo de problema, pasando a recibir un salario de 1041 libras. Emolumentos que, como a todos los demás oficiales, se pagaba por tercios adelantados. También fue recompensado con otras 208 libras que, como los demás oficiales, recibía como ayuda de costa. Durante su mandato vio un buen número de causas de fe por solicitaciones y proposiciones y por tenencia de libros prohibidos, entre ellos de Rousseau o Voltaire. El 13 de marzo de 1792 fue nombrado juez de bienes confiscados, recibiendo un salario complementario de 156 libras $^{3}$. Fray José Albert fue el inquisidor del distrito de Mallorca hasta 1802.

\subsection{El fiscal}

Juan Bautista Sainz Madrazo, de la villa de San Pedro del Romeral, Santander, de 58 años, estudió leyes y cánones en la Universidad de Valladolid. En ella obtuvo el grado de bachiller, concurriendo posteriormente a la de Ávila, donde se licenció y doctoró. Concluidos sus estudios con éxito, asistió cinco años en la pasantía de Santiago Ignacio de Espinosa ${ }^{4}$. Espinosa poco después, concretamente en 1786, sería miembro del Consejo y Cámara de Castilla. Santiago Ignacio de Espinosa en 1742 fue nombrado abogado y relator de la Real Chancillería y Audiencia de Valladolid. Cabe recordar que en 1792 muchos de los consejeros nombrados por Carlos IV, y

${ }^{3}$ AHN, Madrid / Inquisición, 3559 / Exp. 10, «Personal del tribunal de Mallorca», 1793, fol. 4.

${ }^{4}$ El Diccionario Bibliográfico Español, Madrid: RAH, relata algunos aspectos de su biografía, «Espinosa contrajo matrimonio, el 27 de julio de 1744, con María Josefa Cantabrana y Mantilla de los Ríos, natural de Valladolid, hija de Toribia Gabriela Mantilla de los Ríos, natural de Reinosa, y de Juan de Cantabrana y Frías, natural de Valladolid. De esta unión nacieron cuatro hijos: Jacobo María, María Rafaela, Olalla María y Pedro Regalado Espinosa de los Monteros y Cantabrana. Veinticuatro años más tarde se concedió a Espinosa título de fiscal del Consejo de Navarra (16 de junio de 1768) y desde allí ascendió a la fiscalía de lo civil del Consejo de Castilla (3 de marzo de 1783) desde donde pasó a la Fiscalía de la Cámara de Castilla (13 de mayo de 1783). Entretanto había contraído nuevas nupcias en 1778 con Juana María de Salcedo Guzmán y Rivera, hija de los marqueses de Valdefuentes de Alcañiz. Finalmente, por Real Cédula fechada el 29 de abril de 1786 se le libró título de ministro del Consejo de Castilla, plaza en la que despachó hasta su muerte, aunque poco tiempo antes de ella, el 4 de junio de 1794, se había ordenado que cesara en su ejercicio.

En 1782 se habían obrado y aprobado sus pruebas de ingreso a la Orden de Carlos III en calidad de caballero supernumerario y nueve años más tarde se le libró título de barón del Solar de Espinosa (10 de marzo de 1791). Tras su fallecimiento, dado que el primogénito de su primer matrimonio, Jacobo María Espinosa de los Monteros y Cantabrana (Valladolid, 1748 Granada, 1789), fiscal de la Real Audiencia de Barcelona, oidor de la Audiencia y Chancillería Real de Granada (1787), premurió a su padre sin descendencia, fue el segundo hijo varón, Pedro Regalado Espinosa de los Monteros y Cantabrana, el que sucedió en la merced de barón del Solar de Espinosa». 
que eran hombres afines a Floridablanca, fueron cesados de sus puestos (acusados de obtener provechos ilícitos), entre ellos Santiago Ignacio de Espinosa, el gran valedor de Juan Bautista Sainz. Aunque el cese de Espinosa se dictó en 1792, paradójicamente continuó en su cargo, al menos hasta 1794.

Entre los oficios más relevantes de Juan Bautista Sainz cabe destacar que fue abogado de la Real Chancillería de Valladolid, aunque por poco tiempo. A los cuatro meses de ocupar ese cargo, el Inquisidor General le nombró fiscal del Santo Oficio del tribunal de Mallorca. Recordemos también que, en esa misma época, había sido designado canónigo de la catedral de Tortosa. También ocupó el cargo de Chanciller y juez de competencias del reino de Mallorca. Fue el encargado de dirimir los pleitos de competencias que surgían entre las instituciones civiles y las eclesiásticas o la misma Inquisición, por nombramiento del Comandante General, en virtud de reales facultades y aprobación del Consejo de la Santa Inquisición. Su salario era de 1041 libras y una ayuda de costa de 208 libras $^{5}$.

\section{LOS OFICIALES}

Siendo fieles al escalafón y jerarquía interna de la inquisición del reino de Mallorca, entre los distintos oficiales que formaban parte del tribunal hallamos los siguientes cargos y oficios.

Don Jorge Puigdorfila Villalonga, fue alguacil mayor del Santo Oficio de Mallor$\mathrm{ca}^{6}$ por gracia del Obispo de Teruel Francisco Pérez de Prado y Cuesta, Inquisidor General, de fecha 15 de diciembre de 1747, validado por Real Cédula de 18 de dicho mes de diciembre ${ }^{7}$. Casado con Ana Villalonga Truyols, y natural de Palma, pertenecía a la gran oligarquía de Mallorca, siendo caballero. Recordemos que Pérez de Prado tuvo muchos problemas, tanto con el pueblo como con oligarquía del reino, por dos motivos fundamentales. El primero, porque concedió muchos favores a los jesuitas. El segundo, porque poseía un talante extremadamente riguroso con los actos y fiestas públicas y populares lo que generó muchas complicaciones.

El salario de alguacil mayor que recibía Jorge Puigdorfila eran 208 libras que se le pagan por tercios adelantados, así como una ayuda de costa de 78 libras $^{8}$. El Obispo de Jaén, Agustín Rubín de Ceballos, Inquisidor General (que junto a

${ }^{5}$ AHN, Madrid / Inquisición, 3559, / Exp. 10, «Personal del tribunal de Mallorca», 1793, fol. 5.

6,1287 , / Exp. 14, «Informaciones genealógicas de Jorge de Puigdorfila y Villalonga y de Ana de Villalonga y Truyols, su mujer».

7 Ibidem, fol.

${ }^{8}$ AHN, Madrid / Inquisición 3559, / Exp. 10, «Personal del tribunal de Mallorca», 1793, fol. 6.

${ }^{9}$ En 1791 fue reconocido por el rey nombrándolo miembro de la orden de Carlos III, vid. AHN, Madrid / Estado, / Carlos III, / Exp. 521. 
Floridablanca diseñó un cordón sanitario para evitar la propagación de ideas revolucionarias elaborando un nuevo índice de obras prohibidas), el 3 de julio de 1790 le concedió la gracia de jubilado de su empleo de alguacil mayor, pudiendo retener todo su salario y ayuda de costa, dando la propiedad de su plaza a Don Gaspar de Puigdorfila ${ }^{10}$, su hijo, capitán del regimiento de milicias. Al verificarse el fallecimiento de su padre debería recibir su salario. Gaspar de Puigdorfila estaba casado ${ }^{11}$ y en el momento de confección del expediente tenía 41 años.

Don Pedro Téllez Pacheco, de 72 años, fue secretario del secreto, con título del Consejo de fecha 11 de marzo de 1745. Se le despachó cédula otorgándole la mitad de salario y ayuda de costa. Desde el 5 de mayo de 1745 hasta el 9 de junio de 1758 cobró solo la mitad. A partir de esta última fecha se despachó Real Cédula para pagar el íntegro salario que ascendía a 333 libras pagaderas por tercios adelantados, así como una ayuda de costa de 83 libras $^{12}$. Pedro Téllez era natural de la villa de Cassarrubias del Monte, en Toledo, de estado casado, en el momento del expediente tenía tres hijos, dos de los cuales servían en el ejército real, teniendo las plazas de capitán y teniente.

Mariano Manuel Fábregues Mezquida ${ }^{13}$, entró como secretario a tenor del oficio despachado el 18 de octubre de 1768, por jubilación del doctor don Jaime Fábregues ${ }^{14}$, su padre. Fue en esa fecha en que se le confirió dicha Secretaría solo con la mitad de salario y ayuda de costa. La otra mitad se la reservó su padre, recibiendo solo 208 libras ${ }^{15}$ hasta el día 31 de marzo de 1785 en que falleció su progenitor, cuando empezó a cobrar el salario íntegro (que es la misma cantidad que el anterior). Natural de Palma, casado, de 46 años, doctor en ambos derechos por la universidad de este reino, era capitán de milicias y de infantería desde la conquista de Mahón en el año 1782, en donde combatió con la compañía de granaderos. Tenía tres hijos varones y una niña, todos ellos de corta edad.

10 Ibídem, fol. 6.

11 AHN, Madrid / Inquisición 1250, / Exp. 4, "Informaciones genealógicas de Gaspar de Puigdorfila y Villalonga y de Ana María Brondo y Puigdorfila, su mujer, 1790».

12 AHN, Madrid / Inquisición, 3559, / Exp. 10, «Personal del tribunal de Mallorca», 1793, fol. 7.

13 AHN, Madrid / Inquisición, 1323, / Exp. 21, «Información genealógica de Mariano Fábregues y Mesquida, 1768».

${ }^{14}$ AHN, Madrid / Inquisición, 1273, / Exp. 5, «Información genealógica de Jaime Fábregues, natural de Pollença (Mallorca, Baleares), notario, pretendiente a oficial del Tribunal de la Inquisición de Mallorca, 1681».

15 AHN, Madrid / Inquisición, 3559, / Exp. 10, «Personal del tribunal de Mallorca», 1793, fol. 8 . 
Don Salvador Vadell ${ }^{16}$, presbítero, fue secretario del secreto por título que obtuvo del obispo de Salamanca Felipe Beltrán, Inquisidor General, de fecha 6 de julio de 1779. Oficio este del que tomó posesión el 16 de septiembre de dicho año. Vadell tenía un sueldo y ayuda de costa ordinaria que sumaban un total de 416 libras, pagaderas por tercios adelantados, igual que los anteriores. Vadell era natural de Petra $^{17}$, en Mallorca, tenía 52 años, y era graduado en Teología por la universidad de ese reino. Fue beneficiado de la iglesia parroquial de Santa Eulalia, de Palma, desde el año 1764. Cuando accedió al cargo no tenía más renta que 60 libras $^{18}$ que le producían las distribuciones anuales de su beneficiado.

Don Bartolomé Serra y Bennássar ${ }^{19}$, natural de Palma, soltero, de 32 años, casado con María Ventura Ribas Ordinas ${ }^{20}$, era secretario del secreto por título del obispo de Jaén Agustín Rubín, Inquisidor General, de fecha 9 de junio de 1785, título que obtuvo por jubilación de don Manuel Cleto de Santiago, que estuvo casado con Coloma Cier Cerdá ${ }^{21}$. Cleto había sido capitán de infantería y tuvo un salario íntegro y ayuda de costa, que hacían un total de 416 libras que cobró durante su vida. Después la mitad de ese sueldo se pagaría a su mujer, mientras estuviese viva. Bartolomé Serra tomó posesión del dicho empleo el 22 de junio de 1785, que ejecutó sin sueldo alguno hasta el 17 de enero de 1787 en que falleció dicho Manuel Cleto. Sueldo que fue la mitad y la mitad de la ayuda de costa, cobrando la otra mitad la viuda de Cleto. Serra era doctor en Filosofía y en ambos derechos por la universidad de este reino. Fue en el Estudio General donde asumió la cátedra de Vísperas de Civil y en el momento de redacción del informe lo era de Prima de Cánones ${ }^{22}$. Obtuvo el título de consultor del Santo Oficio, y antes había sido abogado de presos en causas de fe.

${ }^{16}$ AHN, Madrid / Inquisición, 1358, / Exp. 10, «Información genealógica de Salvador Vadell Roselló, presbítero, natural de Petra, pretendiente a secretario del secreto del Tribunal de la Inquisición de Mallorca, 1779».

17 De esa misma localidad era natural Junípero Serra, franciscano, que estuvo a cargo de la creación de las misiones en California.

${ }^{18}$ AHN, Madrid / Inquisición, 3559, / Exp. 10, «Personal del tribunal de Mallorca», 1793, fol. 9.

${ }^{19}$ AHN, Madrid / Inquisición, 1208, / Exp. 3, «Información genealógica de Bartolomé Serra y Bennássar de Monaver, natural de Palma de Mallorca y pretendiente a secretario del secreto del Tribunal de la Inquisición de Mallorca, 1785».

${ }^{20}$ AHN, Madrid / Inquisición, 1326 / Exp. 17, «Información genealógica de María Ventura Rivas y Ordines, natural de Palma de Mallorca (Baleares), con motivo de su matrimonio con Bartolomé Serra y Bennássar, secretario del Tribunal de Inquisición de Mallorca».

${ }^{21}$ AHN, Madrid / Inquisición, 3732 / Exp. 266, «Alegación fiscal de la información genealógica de Coloma Cier y Cerdá, natural de Palma, mujer de Manuel Cleto de Santiago, s/d».

${ }^{22}$ AHN, Madrid / Inquisición, 3559, / Exp. 10, «Personal del tribunal de Mallorca», 1793, fol. 13. 
Pedro José Campins ${ }^{23}$, era presbítero, y fue designado secretario supernumerario del Santo Oficio, por gracia del obispo de Jaén Agustín Rubín, Inquisidor General, de fecha 16 de diciembre de 1791. La documentación expresa que Campins tenía libre entrada y ejercicio en el secreto, especialmente cuando este tribunal lo necesitase y llamase para su auxilio. Era natural de Consell, en Mallorca, de edad de 45 años, beneficiado de la iglesia de Santa Eulalia. Por Real Provisión gozaba de unas rentas sobre la iglesia parroquial de Sóller que le producían unas 500 libras, más 60 libras ${ }^{24}$ que recibía del beneficio de Santa Eulalia. El salario de los secretarios fue mayor hasta el año 1721. Desde esa fecha los emolumentos se habían reducido mucho y así mismo no gozaban de las franquezas y derechos, puesto que fueron suprimidos en 1718. Sobre esta misma cuestión los miembros de la Inquisición de Mallorca reclamaron en varias ocasiones al Consejo. Según estos la mayoría del personal inquisitorial tenían crecidas familias. Por haberse aumentado el valor de los víveres y géneros necesarios para mantenerse con la decencia y honor correspondiente a lo visible de su empleo, demandaban continuamente un aumento en sus salarios o la concesión de mercedes especiales, como antaño las habían tenido.

El doctor don Antonio Rotger, presbítero, receptor del Santo Oficio, natural de Palma, de 64 años, graduado en Artes y Sagrada Teología por la universidad de ese reino. Antonio Rotger fue canónigo y poseía un beneficio en la catedral que le proporcionaba unas 90 libras al año. Fue nombrado receptor por título del monarca de fecha 1 de septiembre de 1790, así como por poder del obispo de Jaén, Inquisidor General del 2 de dicho mes y año. Tomó posesión el día 27 de septiembre de 1790, habiendo servido previamente como contador y archivero de la Inquisición de Mallorca bien en ausencia o bien por enfermedades del licenciado Juan Rotger, su tío. Trabajos estos que realizó desde 22 de abril de 1757 y luego por jubilación de este entró en propiedad el 7 de mayo de 1766, en virtud de título de esa fecha. Habiendo fallecido su tío el 25 de abril de 1774, obtuvo el salario y ayuda de costa ordinarios y lo cobró hasta 1790, en que entró como receptor cuyo salario en el momento de la redacción del informe era de 100 libras y una ayuda de costa de 68 libras. Antonio Rotger tenía el privilegio de nombrar un ayudante que podía remover a su voluntad el cual también tendría un salario 100 libras $^{25}$. Rotger nombró asistente a Melchor Guasp, tras comunicarlo al tribunal según lo ordenado por los señores del Consejo.

${ }^{23}$ AHN, Madrid / Inquisición, 1349 / Exp. 6, «Información genealógica de Pedro José Campins, presbítero pretendiente a oficial del Tribunal de la Inquisición de Logroño, 1791». AHN, Madrid / Inquisición, 1348 / Exp. 8 «Información genealógica de Pedro José Campins, natural de Consell, clérigo de tonsura, pretendiente a oficial del Tribunal de la Inquisición de Mallorca, 1763».

${ }^{24}$ AHN, Madrid / Inquisición, 3559, / Exp. 10, «Personal del tribunal de Mallorca», 1793, fol. 14.

${ }^{25}$ AHN, Madrid / Inquisición, 3559, / Exp. 10, «Personal del tribunal de Mallorca», 1793, fol. 15 . 
También tenía dos exactores para la cobranza de las rentas de la dotación y Real Fisco y les pagaba sus trabajos de exacción de lo que tocaba al receptor, según la calidad de sus créditos, pagos que debería anotar en las cuentas que debía presentar cada dos años.

Guillermo Roca, fue nombrado abogado del Real Fisco de la Inquisición de Mallorca. Estaba casado, era graduado en ambos derechos por la universidad de este reino, de 50 años, y natural de Palma. Sirvió desde el 23 de abril de 1770 como interino, y después se le nombró titular por el arzobispo de Farsalia Manuel Quintano Bonifaz, Inquisidor General, de fecha 9 de junio de 1793. Su salario también se pagaba por tercios adelantados, y ascendía a 65 libras. Así mismo debía cobrar 100 ducados de ayuda de costa de los emolumentos de la Curia de bienes confiscados, pero como estos en ocasiones no alcanzaban la totalidad, solo cobraba su parte correspondiente ${ }^{26}$.

Francisco Mariano de Villalonga, contador y archivero del Santo Oficio de Mallorca por título real de fecha 9 de diciembre de 1791, y por poder del obispo de Jaén, Inquisidor General, de 2 de diciembre de 1791. Tomó posesión de su empleo el 7 de enero de 1792. Villalonga era natural de Palma, casado, de 31 años y poseía numerosos bienes. No obstante, su posición acomodada, tenía un salario de 212 libras, y 60 libras de ayuda de costa ${ }^{27}$.

Antonio Pablo Coll Salom, oficial mayor de la contaduría, por título del obispo de Jaén, Inquisidor General, de fecha 10 de noviembre de 1789, con salario de 120 libras $^{28}$, era abogado de presos en causas de fe, y antes fue nuncio del secreto del Santo Oficio de ese reino. Antonio Pablo Coll era soltero, natural de Palma, de 30 años, y socio de la Real Academia Matritense.

Pedro Juan Fonollar fue designado por el obispo de Salamanca, Inquisidor General, como notario propietario de los secuestros y de los bienes confiscados y causas civiles, de fecha 7 de febrero de 1778, en la misma forma que lo fue don Cristóbal Fonollar, su padre. Tomó posesión de su cargo el 3 de abril de 1778. Pedro Juan Fonollar era natural de Palma, casado, de 55 años, no tenía salario como notario de los bienes confiscados y causas civiles, puesto que ya cobraba los emolumentos de los pleitos. En cambio, por la notaria de secuestros su salario fue de 246 libras. Además de los cargos en el Santo Oficio, también fue notario público. Fue miembro de la Sociedad Económica de Amigos del País de Mallorca ${ }^{29}$.

${ }^{26}$ AHN, Madrid / Inquisición, 3559, / Exp. 10, «Personal del tribunal de Mallorca», 1793, fol. 16.

${ }^{27}$ AHN, Madrid / Inquisición, 3559, / Exp. 10, «Personal del tribunal de Mallorca», 1793, fol. 17.

28 Ibidem.

${ }^{29}$ AHN, Madrid / Inquisición, 3559, / Exp. 10, «Personal del tribunal de Mallorca», 1793, fol. 18. 
Bartolomé Quart, procurador del Real Fisco del Santo Oficio de Mallorca, natural de Palma, de 60 años, soltero, graduado en ambos derechos, por esa universidad, sirvió desde el 9 de septiembre de 1769, por título otorgado por el arzobispo de Farsalia, Inquisidor General, con un salario 210 libras $^{30}$, por tercios adelantados. Anteriormente había sido abogado de presos en causas de fe.

Antonio Pablo Togores, alcaide de las cárceles secretas por título del obispo de Salamanca, Inquisidor General, de fecha 2 de mayo de 1782, por fallecimiento de don Pedro Riutort, alcaide retirado. Tenía un salario de 150 libras, y 40 libras $^{31}$ de ayuda de costa, casado, de 53 años. Por razón de su oficio poseía una casa habitación que estaba unida con la sede de la Inquisición.

Gabriel Aloy Vaquer ${ }^{32}$, nuncio del secreto, jubilado, con el sueldo entero de 150 libras $^{33}$ por gracia del obispo de Jaén, Inquisidor General, nombrado el 27 de noviembre de 1786, viudo, estuvo casado con Antonia Ramis, natural de Palma, de 61 años.

Matías Mateu Rotger, de Palma, soltero, 34 años, nuncio del secreto por jubilación del antecedente. Obtuvo el puesto por título otorgado por el Inquisidor General y obispo de Jaén. El 13 noviembre de 1789 se le concedió el salario íntegro por fallecimiento de Gabriel Aloy, su antecesor ${ }^{34}$.

Pedro Josep Campins ${ }^{35}$, portero de cámara del Santo Oficio, por título del arzobispo de Farsalia, tomó posesión de su cargo el 21 de junio de 1763. Campins tenía un salario 150 libras $^{36}$, era natural de Consell, casado, de 56 años. En el momento de la redacción del expediente postulaba por un aumento en el escalafón inquisitorial a oficial del Santo Oficio de Logroño.

Bernardo Nadal fue proveedor de cárceles secretas, y ayudante de alcaide, por título del obispo de Salamanca, Inquisidor General, de fecha 4 de mayo de 1782. Al fallecer Pedro Riutort, alcaide jubilado con el sueldo entero, comenzaría a disfrutar-

30 Ibídem.

31 Ibidem.

32 AHN, Madrid / Inquisición, 1249, / Exp. 5, «Informaciones genealógicas de Gabriel Aloy Baquer, natural de Palma de Mallorca (Baleares), pretendiente a oficial del Tribunal de la Inquisición de Mallorca y de su mujer, Antonia Ramis, natural de Sencelles, 1754».

${ }_{33}$ AHN, Madrid / Inquisición, 3559, / Exp. 10, «Personal del tribunal de Mallorca», 1793, fol. 19.

34 Ibidem.

35 AHN, Madrid / Inquisición, 1348, / Exp. 8, «Información genealógica de Pedro José Campins, natural de Consell, clérigo de tonsura, pretendiente a oficial del Tribunal de la Inquisición de Mallorca, 1763». AHN, Madrid / Inquisición, 1349, / Exp. 6, "Información genealógica de Pedro José Campins, presbítero, natural de Palma, en el Reino de Mallorca, pretendiente a oficial del Tribunal de la Inquisición de Logroño, 1791».

${ }^{36}$ AHN, Madrid / Inquisición, 3559, / Exp. 10, «Personal del tribunal de Mallorca», 1793, fol. 19. 
lo el dicho Antonio Pablo Togores alcaide en propiedad. A partir de ese momento Nadal percibiría 50 libras $^{37}$. Habiéndose verificado la muerte de dicho alcaide jubilado Pedro Riutort el 20 de septiembre de 1791, comenzó a cobrar las 50 libras. Bernardo Nadal era natural de Bunyola, casado, de 41 años. Tuvo una casa unida a la del tribunal para que pudiera proveer a los presos. Asimismo, por el trabajo de preparar las comidas cada día se le dieron dos cuartos diarios por cada uno de los presos que hubiera en la prisión.

\section{CONSULTORES Y FAMILIARES}

El resto de personal de la isla no tenía ningún salario y siempre los designaba el inquisidor. El único que recibía un pequeño emolumento por sus servicios era el médico y cirujano de los presos. Se le pagaba anualmente, tal y como quedaba perfectamente reflejado en las cuentas que presentaba el receptor.

En cuanto a los calificadores existentes en 1793 había un total de catorce, a saber: Francisco Andrés Obrador, provincial, mínimo; maestro Pio Puigserver, dominico; Pedro Torrandell, cura párroco de la iglesia de Santiago, de Palma; Bartolomé Verd, cura párroco de la iglesia de Manacor y que también lo fue de Sencelles. Verd impartió clases de Filosofía en el Estudio General Luliano, por entonces la universidad de la isla; Antonio Climent, cura de Llucmajor; Tomás Español, dominico; provincial Josep Fullana, mínimo, ausente en Roma; lector jubilado Mateo Canyellas, mínimo; lector jubilado Rafael Barceló, mínimo; Jaime Antonio Obrador, cura de Andratx; lector jubilado Guillermo Lledó, agustino; provincial Miguel Pellicer, franciscano; Matías Espinosa, cura de Montuïri y fray Pedro Pizá, franciscano.

Por su parte, los consultores eran cinco: Juan Bautista Roca, oidor de la Real Audiencia y del Consejo Real; Guillermo Roa, Bartolomé Quart; Antonio Climent y Marcos Ignacio Rosselló.

Dada la existencia de varios lugares marítimos, también se designó un comisario en Artá, el doctor Don Miguel Font; y otro más en Pollença, el doctor Miguel Vila ${ }^{38}$.

Con relación al número de familiares de Mallorca no existía ninguna concordia con la jurisdicción Real ni otra ley que una ordenación hecha por el inquisidor Hevia de Oviedo en el año 1603, reflejando unos cien familiares para toda la isla. No obstante, en 1792 entre caballeros y otras clases solo había diecinueve. La explicación que se dio por esta caída significativa en el número de familiares fue porqué se habían eliminado todas sus exenciones y privilegios. El capitán de familiares era don

37 Ibidem.

38 AHN, Madrid / Inquisición, 3559, / Exp. 10, «Personal del tribunal de Mallorca», 1793, fol. 21. 
Francisco Villalonga Mir, caballero de la orden de Santiago, con título del obispo de Salamanca, Inquisidor General, de 9 de marzo de 1779.

En las villas, los familiares eran casi inexistentes. En esos momentos solo diecisiete, la mayoría de avanzada edad, por lo que el tribunal remarcó que se necesitaban muchos más al haber un gran número de pueblos y algunos de ellos con importantes puertos de mar $^{39}$.

\section{LOS OFICIALES EN MENORCA E IBIZA}

En Menorca durante siglos se habían institucionalizados dos comisarios y hasta 20 ministros y familiares, pero en 1792 no existía ninguno. Cabe recordar que en 1715 por orden del Consejo se suspendió el ejercicio de sus empleos dado que los ingleses ocupaban aquella isla. El 23 de octubre de 1749 el obispo de Teruel, Inquisidor General, dio comisión al obispo de este reino José de Cépeda, y al vicario general de Menorca para que pudieran conocer las causas de fe. Esa comisión la repitió de nuevo el Inquisidor General, arzobispo de Farsalia al obispo de Mallorca y arzobispo de Tarragona, don Lorenzo Despuig, por luliano y de carácter moderado, con fecha 4 de agosto de 1756 y luego las vio Antonio Roig, vicario general de Menorca con aprobación de los señores del Consejo ${ }^{40}$.

En la isla de Ibiza, con una población muy diseminada, había un comisario y cuatro notarios extraordinarios, todos ellos calificados como personas honestas, así como cuatro familiares para servir los empleos de alguacil, fiscal, notario y demás necesarios. El comisario se servía de ellos en momentos puntuales de acuerdo con su idoneidad.

\section{CONCLUSIONES}

La Inquisición siempre fue hija de su tiempo, y los hombres que formaron parte de esta, en consecuencia, tenían las preocupaciones, temores y esperanzas inherentes a la sociedad. A finales del siglo XVIII los momentos de persecución de los judaizantes, brujas, hechiceras o renegados habían sido superados por otros problemas, en especial la influencia de las nuevas ideas de la llustración (fundamentalmente por las surgidas en Francia). De ahí que la actividad del tribunal isleño se centrase básicamente en dos cuestiones: los solicitantes, puesto que aún detecta-

39 Ibidem, fol. 22.

40 AHN, Madrid / Inquisición, 3559, / Exp. 10, "Personal del tribunal de Mallorca», 1793, fol. 24. 
mos algunos procesos contra eclesiásticos derivados de esas cuestiones; y contra la tenencia o difusión de libros prohibidos (el proceso contra el doctor Fiol es una clara muestra de ello). De ahí que no cabe ninguna duda sobre que el tribunal de la Inquisición del distrito de Mallorca a finales del siglo XVIII estaba en franca decadencia. No obstante, los gastos derivados de los salarios del personal ascendían a unas 6000 libras mallorquinas, una cantidad muy elevada dada la actividad ejercida por los mismos. Otra de las cuestiones que nos llaman la atención, después de analizar la nómina del personal adscrito al tribunal, es que hallamos una clara cooptación en la elección de determinados oficios que fueron transmitidos de padres a hijos.

Una más de las conclusiones que hemos alcanzado es la de valorar las conexiones que se dieron en la institución inquisitorial, especialmente entre los altos cargos, configurando de esa forma una verdadera red de poder que se extendía gradualmente por todos los territorios de la Corona. Un ejemplo evidente de ello es la relación que se forjó entre Juan Bautista Sainz Madrazo, que fue nombrado fiscal del tribunal de Mallorca, y Santiago Ignacio de Espinosa.

Finalmente, cabe explicar que las diferencias existentes en materia de personal entre Mallorca y las de Ibiza y Menorca fueron muy importantes, tanto en materia de personal como también de infraestructuras. En cuanto a Menorca incidir en que, tras la primera ocupación británica, el Santo Oficio quedó totalmente desmantelado.

\section{REFERENCIAS BIBLIOGRÁFICAS}

Aguilar Piñal, F. (1968). La Real Academia Latina Matritense en los planes de la Ilustración. Anales del Instituto de Estudios Madrileños, 3, pp. 183-217.

Cañas Murillo, J. (2004). Inquisición y censura de libros en la España de Carlos III: la Real cédula de junio de 1768. Anuario de Estudios Filológicos, 27, pp. 5-11.

Coll Coll, A. M. a (2018). Opciones y oportunidades en la carrera administrativa del siglo XVIII: burócratas y militares entre las redes de poder de Mallorca. Revista de Historia Moderna. Anales de la Universidad de Alicante, 36, pp. 147-180. https://doi.org/10.14198/RHM

Ferrer Florez, M. (2001). Las órdenes religiosas en Mallorca a fines del siglo XVIII y principios del XIX. Bolletí de la Societat Arqueològica Lul. liana: Revista d'estudis històrics, núm. 57, pp. 171-202 
Ferrer Florez, M. (2007). La 'Guerra Gran' (1793-1795). Memòries de la Reial Acadèmia Mallorquina d'Estudis Genealògics, Heràldics i Històrics, 17, pp. 115145.

García Pérez, F. J. (2017). El Cabildo de Mallorca y el vicario general sede vacante durante el Setecientos: disputas y ámbitos de poder. Revista de Historia Moderna. Anales de la Universidad de Alicante, 36, pp. 497-529. https://doi. org/10.14198/RHM

Gil González, F. (2017). La represión de las nuevas formas de sociabilidad en el siglo XVIII: procesos seguidos por el tribunal de la Inquisición a los masones. RDUNED: revista de derecho UNED, 20, pp. 319-332. https://doi.org/10.5944/ rduned.20.2017.19478

Gil Saura, Y. (2019). Memoria de un espacio montesiano desaparecido: la Iglesia y Colegio de San Jorge en la ciudad de Valencia. En Y. Gil; A. Ester; E. Guinot, E. (eds.), La Orden de Montesa y San Jorge de Alfama (pp. 45-72). València: Universitat de València.

Gómez Rivero, R. (2004). Consejeros de Castilla Catalanes (1788-1834). lus fugit: Revista interdisciplinar de estudios histórico-jurídicos, 13, pp. 309-330.

Gómez Rivero, R. (2005). Ministros del consejo de Castilla (1814-1820). Anuario de historia del derecho español, 25, pp. 277-330.

Juan Vidal, J. (2010). La conquista inglesa de Menorca. Un capítulo de la guerra de Sucesión a la Corona de España. Palma: El Tall.

Mari Brull, G. (2007). Metges catalans perseguits per la inquisició al segle XVIII acusats de proposicions: Agustí Tamarit, de Salàs, i Domingo López, de Sant Feliu de Llobregat. Gimbernat: Revista d'Història de la Medicina i de les Ciències de la Salut, 47, pp. 95-117.

Pérez, L. (1972). Sobre el lulismo del obispo de Mallorca, Don Lorenzo Despuig. Estudios Lulianos, 17, pp. 197-204.

Planas Rosselló, A. (2002). Los juristas mallorquines del Siglo XVIII. Memòries de la Reial Acadèmia mallorquina d'Estudis Genealògics, Heràldics i Històrics, 12, pp. 37-97. 
Quintana Ripollés, A. (1992), Gracia y desgracia de un inquisidor general de España e Indias en las Cortes de Fernando VI y Carlos III. Anales de la Real Academia Matritense de Heráldica y Genealogía, 1, pp. 275-298.

Torres Arce, M. (2010). Inquisición y control de la sociedad urbana a fines del Antiguo Régimen. Anuario IEHS: Instituto de Estudios histórico sociales, 25, pp. 205-230. 